\title{
Ethical, Legal, and Administrative Considerations for Preparticipation Evaluation for Wilderness Sports and Adventures
}

\author{
Craig C. Young, MD; Aaron D. Campbell, MD, MHS; Jay Lemery, MD; David S. Young, MD \\ From the Departments of Orthopaedic Surgery and Community and Family Medicine, Medical College of Wisconsin, Milwaukee, Wisconsin \\ (Dr C. C. Young); Family and Sports Medicine, University of Utah, Salt Lake City, Utah (Dr Campbell); the Department of Emergency Medicine, \\ University of Colorado School of Medicine, Aurora, Colorado (Dr. Lemery); and the Department of Emergency Medicine, University of Colorado, \\ Denver, Colorado (Dr D. S. Young).
}

\begin{abstract}
Preparticipation evaluations (PPEs) are common in team, organized, or traditional sports but not common in wilderness sports or adventures. Regarding ethical, legal, and administrative considerations, the same principles can be used as in traditional sports. Clinicians should be trained to perform such a PPE to avoid missing essential components and to maximize the quality of the PPE. In general, participants' privacy should be observed; office-based settings may be best for professional and billing purposes, and adequate documentation of a complete evaluation, including clearance issues, should be essential components. Additional environmental and personal health issues relative to the wilderness activity should be documented, and referral for further screening should be made as deemed necessary, if unable to be performed by the primary clinician. Travel medicine principles should be incorporated, and recommendations for travel or adventure insurance should be made.
\end{abstract}

Key words: preparticipation evaluation, wilderness medicine, ethics, legal

\section{Introduction}

The ethical, legal, and administrative considerations that apply to sports preparticipation evaluations (PPEs) can be extrapolated from conventional or team sports and applied to wilderness sports or adventure activities. These have not been previously described in the literature. By taking conventional ideas and principles of traditional sports PPE and applying them to the unconventional, austere, and often remote, wilderness environment, a PPE for the wilderness sports and adventures can be performed in much the same way. This article reviews the current literature on ethical, legal, and administrative issues for traditional sports PPE and applies these

This article appears in a "Care of the Wilderness and Adventure Athlete" special issue, jointly published by Clinical Journal of Sport Medicine and Wilderness \& Environmental Medicine.

Jay Lemery MD is a former president of the Wilderness Medical Society, is a consultant to the Centers for Disease Control and Prevention (CDC) and has received royalties from Rowman \& Littlefield. The remaining authors report no conflicts of interest.

Corresponding author: Craig C. Young, MD, $9200 \mathrm{~W}$ Wisconsin Ave Box 26099, Milwaukee, WI 53226-0099 (e-mail: cyoung@mcw.edu). principles to wilderness sports and adventures, making specific recommendations for this population.

\section{Methods}

Authors searched the MEDLINE database from 1946 to present via PubMed and OVID with the key terms ethics, jurisprudence, preparticipation, and injury prevention. Studies were limited to the English language. These articles were reviewed, and if applicable, they were integrated into the current article. Additionally, we relied upon the format as presented by Bernhardt and Roberts ${ }^{1}$ for the traditional PPE model, to translate to wilderness athletes and adventurers.

\section{Results}

Findings of the literature review of selected published articles and recommendations from the book PPE: Preparticipation Physical Evaluation, fourth Ed. $2010^{1}$ were consolidated and translated to wilderness athletes and adventurers as discussed in the sections below. 


\section{ETHICAL CONSIDERATIONS}

The ethical considerations of the traditional PPE revolve around the balance of "the right to participate" versus the principles of "do no harm."1,2 Similarly, the traditional ethical tenets for wilderness medicine are as follows: (1) do no harm, (2) beneficence (welfare of the participant), (3) autonomy (freedom from external control), and (4) justice. $^{3-5}$ These ethics and those of climbing and mountain sport participation can be transposed into other austere or remote environments. ${ }^{6}$ The differences and similarities between the conventional sports PPE and the PPE for wilderness sports and adventures are not always obvious. However, the established PPE principles are relevant for clinicians who evaluate wilderness athletes or adventurers. This is true in the preparticipation setting, or during care for individuals in wilderness environments, with modifications to address the specific risks of the wilderness environment.

As with many physical examinations, it is possible that individuals seeking a PPE before a wilderness event have not had a physical examination by another clinician in quite some time. Often, it is the event itself that prompts the request for a physical examination by the individual. In other cases, such as guided mountaineering expeditions, participants may have been asked to have an evaluation by a clinician to ensure health while on the trip.

Fundamentals of the PPE involve an opportunity to cover elements of a standard sport screening and a preventive physical examination, as well as sportspecific screening. The majority of health issues will be identified by the history alone, and the goal is not to disqualify rather to identify health risks and strive for prevention. ${ }^{1}$ The evaluation should be as follows: (1) professional; (2) involve common sense and an explanation of the process and components of the history and physical examination; and (3) observe gender-specific issues. Clinicians performing the PPE should be adequately trained and well versed in the principles of the PPE and sport-specific issues, using literature-based references whenever available. Additional referral may be necessary depending on issues that may be identified. ${ }^{2}$

Ultimately, the clinician has a responsibility to clear or restrict the participant for his or her planned activity. Clearance can be without restriction, clearance with specific recommendations, or restriction, either with special accommodation or complete disqualification depending on the issue. Disqualification is rare and not the goal of the PPE. As of 2011, Peterson and Bernhardt state, "In the largest evaluation of the PPE only $1.9 \%$ of 2729 high school athletes were disqualified from sports participation, and only $11.9 \%$ required any type of follow up evaluation." ${ }^{, 7}$ Disqualification or restriction is seldom made by a single clinician but rather in combination with an appropriate specialist after a thorough and issue-specific evaluation. If restricted or disqualified, participants may elect to seek a second opinion or legal consultation. The clinician must prepare thorough documentation to state objective facts about the findings, specialty consultation recommendations, and reasons for restriction or disqualification.

The issues pertaining to minors participating in wilderness sports or adventures warrant focused consideration. The PPE for minors should be viewed in a similar fashion as adults in that a standard well child or sports physical should include attention to immunizations, vital signs, visual acuity, body mass index, current physical condition, identification of any active health issues, and anticipatory guidance, in addition to any particular issues that are pertinent to the proposed activity. In cases in which the parents will also be involved in the wilderness sport or adventure, the health of the child should be considered independent of the goals of the family.

Clinicians performing a PPE should understand that any sport has inherent risk, yet wilderness sports and adventures may pose higher risks than conventional sports conducted in more controlled environments based on the remote or austere setting in which they typically take place. Risk tolerance is relative to the individual, and ultimately, acceptance of that risk should be up to the individual assuming that there is no personal history or physical examination findings suggesting an increased risk or harm by participating.

Participants in wilderness activities should be made aware that although they may not meet disqualification criteria, they might actually hinder an expedition due to health conditions, and group dynamics and risks should be considered. Documentation should involve the participant completion of a health history form that the clinician has reviewed. Any additional focused intervention should take place based on the history and physical condition. Counseling should also be documented and directed toward where to find additional information. Referral to a specialist more skilled in a specific area of wilderness medicine should be used when necessary. This may include referral to a clinician trained in conducting a wilderness sports or adventure PPE.

\section{LEGAL CONSIDERATIONS}

The PPE is often required for participants before organized wilderness sports or adventures. The findings may be important for the safety and comfort of the 
participants. In most cases, organizers of wilderness sports or adventures will have the legal right to restrict participation as long as the decision is individualized, reasonable, and based on sound medical evidence. ${ }^{1}$ Due to concerns of disqualification, some participants with chronic medical conditions may be dishonest on their medical history forms to be allowed to participate, distorting the accuracy of their health history. Unfortunately, this sets up potentially dangerous situations not only for the individual but also for other participants of the activity, and the organizers. The Dive Alert Network has recorded many cases of diving accidents that may have been prevented if the participants had not falsified their medical forms. ${ }^{8}$

Organizers will commonly have participants sign "exculpatory waivers" or "risk releases" before allowing participation. These releases state that the participant understands the risk of participation and accepts the potential consequences. Often, they are written by a third party, requesting a clinician signature for clearance. If used by the evaluating clinician, waivers should focus on activity specifics, and additional documentation may be needed to support the clinician recommendations. If such waivers are written too broadly (eg, to waive liability from gross negligence, reckless, or intentional actions), the courts have, in the past, invalidated the waiver. ${ }^{9}$ In addition, the court system usually does not allow the legal rights of minors to be waived, even by their parents. ${ }^{10}$ Some legal experts recommend that a letter of informed consent be written by the participant and his or her parents rather than signing a waiver. Ideally, this wavier will be handwritten by the participant in which he or she states what risks he or she has been told about. ${ }^{11,12}$

In general, clinicians performing PPEs for wilderness sports and adventures should not count on the Good Samaritan law for protection from liabilities related to performing PPEs on a volunteer basis. Evaluating clinicians should ensure that their professional liability insurance covers performing these PPEs. ${ }^{1}$ In many cases, this situation can be avoided if performed in a formal office-based setting, using typical documentation and billing methods.

\section{ADMINISTRATIVE CONSIDERATIONS}

Preparticipation evaluations for participants embarking on a wilderness sport or adventure should be performed early in trip planning, especially if there is 1 medical director for an expedition organization who will be required to perform evaluations for the entire group of participants. Medical screening of individuals take significant time to schedule, and if a large number of individuals are joining an expedition, special planning and foresight are required to efficiently evaluate all members of the expedition. Additionally, full clearance may involve multiple encounters. It is possible in these situations that a formal face-to-face evaluation may not take place. Clinicians are often tasked with reviewing health history forms and making recommendations for further assessment. In other cases, clinicians may meet with individual participants through Internet or telephone encounters. For example, a participant may be given a recommendation to visit a travel clinic for immunizations, a dentist if his or her past dental examination was remote, an optometrist for vision screening, or other medical specialists if a participant has chronic medical conditions. Coordinating multiple encounters like these inevitably takes time. Therefore, it is recommended that participants should be evaluated soon after a roster is compiled. Finding a participant may not be cleared for a wilderness sport or adventure too near the event can have significant financial and logistical repercussions. Based on recommendations for traditional PPEs, to allow time for further evaluation, treatment, or rehabilitation from an issue of concern, the authors recommend that a PPE occurs a minimum of 6 weeks before the date of starting the wilderness sport or adventure. ${ }^{1}$ In certain unique situations, it may be necessary to initiate a PPE much earlier than this time frame. For example, some guided expeditions, such as those to high altitude peaks in Denali National Park, Alaska, and similar trips to South America, require a PPE be performed within the past 1 year before participation and be submitted up to 120 days in advance. ${ }^{13}$ Private expeditions to Mount McKinley in Denali National Park require a 60-day preregistration application by the Denali National Park Service. ${ }^{14}$ Other similar situations may apply depending on the nature of the activity. It behooves the evaluating clinician to be aware of such environment-specific details if performing a PPE for a wilderness sport or adventure.

It is possible for both physicians and advance practice clinicians to perform a PPE for wilderness athletes and adventurers and to bill for such encounters. Billing would be the same as for a traditional sports physical examination done for high school or college athletes. These evaluations have variability in reimbursement by health insurance companies. The American Medical Association recommends using Current Procedural Terminology (CPT) codes 99201 to 99215 for preventative visits that are less than comprehensive. Currently, there is no code for a PPE. In situations when an insurance provider does not pay for these visits, the American Academy of Family Physicians (AAFP) recommends 1 of 2 options. ${ }^{15,16}$ The first option is to complete a full preventive annual examination and bill as such. 
Typically, payers reimburse for 1 preventive examination yearly, so this can only be used if the individual has not already had his or her annual examination in the past 12 months. The clinician must complete a comprehensive history and physical examination with counseling and anticipatory guidance appropriate for the individual. The second option that the AAFP recommends is performing a typical PPE, but billing the individual for this visit, explaining that one's health plan may not pay for the visit. ${ }^{17}$ If stand-alone disease diagnoses are pertinent to the evaluation, appropriate evaluation and management CPT codes may be used.

Multiple forms for PPEs exist online, including examples provided by the American Academy of Pediatrics and the AAFP, in addition to those provided by PPE: Preparticipation Physical Evaluation, fourth $E d .{ }^{1,15,16}$ However, because these forms are based on clearance for school sports, they should be used only as a general framework. To the knowledge of the authors, there are no published forms specific to wilderness sports or adventures. In developing a wilderness sports-specific or adventure-specific form, the clinician should take into consideration the participant's previous experience with the activity, symptoms, or problems experienced during previous participation, psychiatric history, or other medical conditions that may be exacerbated by the environments that may be experienced. The authors suggest starting with a traditional PPE form and supplementing this with the appropriate content and additional considerations pertinent to the wilderness sport or adventure.

Preventing infectious disease on a wilderness sport or adventure is paramount to a safe experience. To ensure that all steps are taken, completion of recommended vaccinations appropriate for the destination is essential. This may simply be a tetanus booster, but for more exotic locations, vaccinations for polio, Japanese encephalitis, rabies, or other diseases may be indicated. Hepatitis and typhoid vaccine needs are common, and the need for malaria prophylaxis should be assessed. In addition, prophylactic medications may be necessary. Determining which vaccinations and medications are appropriate is beyond the scope of this article. However, using the recommendations and resources found at the Center for Disease Control (travel section) or working closely with a travel clinic is prudent. Setting up a close working relationship with an infectious disease specialist at these clinics will ensure appropriate vaccinations and medications for the travelers if the organizers are unable to do so. ${ }^{18}$

Occasionally, pharmacists will hesitate at filling prescriptions for multiple medications prescribed to an otherwise healthy individual, especially when there is no clear treatment pattern for the types of medications. This can often be avoided by including a comment on the prescriptions that the medications are for an upcoming activity. Insurance companies often have no problem paying for these medications and immunizations, but there are exceptions, and some participants will have to pay out of pocket. If a problem does arise, speaking directly with the insurance provider may resolve issues.

\section{Summary}

Although the PPE for wilderness sports and adventures may be straightforward in most cases, occasionally, clinicians will be faced with challenges in which the individual is willing to accept increased risks to participate in an activity. In wilderness sports or adventures involving other individuals, such as on a team or guided expedition, this may result in the entire party being placed at risk. Thus, clinicians need to carefully balance ethical issues while considering administrative and legal issues when performing PPEs for wilderness sports and adventures.

\section{References}

1. Bernhardt DT, Roberts WO. PPE Preparticipation Physical Evaluation. 4th ed. Elk Grove Village, IL: American Academy of Pediatrics; 2010.

2. Pearsall AWT, Kovaleski JE, Madanagopal SG. Medicolegal issues affecting sports medicine practitioners. Clin Orthop Relat Res. 2005;433:50-57.

3. Auerbach PS. Wilderness Medicine. 6th ed. Philadelphia, PA: Elsevier/ Mosby; 2012;xxv:2277.

4. Stokes S, Mackenzie S, Thomas C. Medical ethics in mountain and wilderness medicine. J R Army Med Corps. 2011;157:124-126.

5. Wilkerson JA. Medicine for Mountaineering \& Other Wilderness Activities. 5th ed. Seattle, WA: The Mountaineers Books; 2001:366.

6. UIAA. Mountain ethics declaration. 2009. http://www. alpineclubofcanada.ca/environment/forms/UIAA_Mountain_ Ethics_Declaration_web.pdf. Accessed March 30, 2014.

7. Peterson AR, Bernhardt DT. The preparticipation sports evaluation. Pediatr Rev. 2011;32:e53-e65.

8. Nord D. To lie or not to lie? Alert Diver. 2010. Web Site. http://www.alertdiver.com/To_Lie_or_Not_to_Lie. Accessed February 28, 2014.

9. Bruett K. Can Wisconsin businesses safely rely upon exculpatory contracts to limit their liability? Marq L Rev. 1998;81:1081-1100.

10. Mitten M. Emerging legal issues in sports medicine: a synthesis, summary and analysis. St Johns L Rev. 2002;76: 100-182.

11. Jones C. College atheletes: illness or injury and the decision to return to play. Buffalo L Rev. 1992;40:113-115. 
12. Mitten M. Team physicians and competetive athletes: allocating legal responsibility for athletic injuries. Univ Pittsburg L Rev. 1993;55:129-169.

13. Alaska Mountaineering School. Applying for an AMS expedition. http://www.climbalaska.org/apply-expeditions. html. Accessed June 14, 2015.

14. National Park Service, U.S., Department of the Interior. Denali national park service clmbing registration. 2014. http://www.nps.gov/dena/planyourvisit/registrationinfo.htm. Accessed July 3, 2014.

15. American Academy of Pediatrics. Preparticipation evaluation forms. http://www.aap.org/en-us/professional-resour
ces/practice-support/pages/Preparticipation-Physical-E valuation-Forms.aspx. Accessed April 5, 2014.

16. American Academy of Family Physicians. Preparticipation physical evaluation: physical evaluation form. 2014. http:/ www.aafp.org/dam/AAFP/documents/patient_care/fitness/ ppephysicalexamform2010.pdf. Accessed June 14, 2015.

17. Hughes C. Sports physicals: a coding conundrum. Fam Pract Manag. 2006;13:39-40.

18. Centers for Disease Control and Prevention. Traveler's health. http://wwwnc.cdc.gov/travel/destinations/list/? s_cid=cdc_homepage_topmenu_ 003. Accessed July 3, 2014. 